\title{
Public and Private Values
}

\section{Dan Ariely, Anat Bracha, and Jean-Paul L'Huillier}

\begin{abstract}
:
This paper experimentally examines whether looking at other people's pricing decisions is a type of heuristic - a decisionmaking rule - that people use even when it is not applicable, as in the case of clearly private value goods. We find evidence that this indeed is the case-an individual's valuation of a purely subjective experience under full information, elicited using an incentive compatible mechanism, is highly influence by valuations made by others. This result can shed light on price behavior, price rigidities, and rents.
\end{abstract}

\section{JEL Classifications: J64, E24, J11}

Dan Ariely is the James B. Duke Professor of Behavioral Economics at Duke University's Fuqua School of Business. His e-mail address is dandan@duke.edu. Anat Bracha is an economist at the Federal Reserve Bank of Boston; her email address is anat.bracha@bos.frb.org. Jean-Paul L'Huillier is completing his Ph.D. in the department of economics at the Massachusetts Institute of Technology. His e-mail address is lhuill@mit.edu.

This paper, which may be revised, is available on the web site of the Federal Reserve Bank of Boston at http://www.bos.frb.org/economic/wp/index.htm.

The authors thank Peter Diamond, Nina Mazar, Daniel Mochon, Kristina Shampanier, Andrei Shleifer, and Ray Weaver for comments and suggestions.

The views expressed in this paper are those of the author and do not necessarily represent those of the Federal Reserve Bank of Boston or the Federal Reserve System.

This version: June 28, 2010 


\section{Introduction}

In many real-life situations before we make our own decisions, we find that it is useful to look at what others have done when they were facing similar choices. For instance, when considering a job offer we might consult others who recently accepted or rejected a related job offer. When purchasing an apartment we might seek information about what prices were paid recently for similar apartments, especially for those transactions taking place in the same neighborhood or even in the same building.

This general strategy is often a very useful one, as many, if not most, of the situations we encounter include some component of common values. This means that relying on others' decisions or on the prices they are willing to pay - as both of these signals convey some relevant information-can be helpful for making our own decisions. While this strategy is often a good one, at times applying it can be inappropriate. One notable example where following others is inappropriate is information cascades, where individuals fail to realize the information externality of their actions (Banerjee 1992; Bikhchandani, Hirshleifer, and Welch 1992; Simonsohn and Ariely 2008). Another instance is Asch's famous "line" experiment (Asch 1951) demonstrating that even in making visual judgments, the majority can influence individual perspectives and decisions, a common result for a range of social behaviors (see Petty and Wegener 1998 for a survey).

In this paper we examine if relying on the behavior of others can also occur in the case of pricing decisions for goods that are private value goods. Specifically, we ask whether looking at other people's pricing decisions is a type of heuristic, meaning a decisionmaking rule, that people over-apply even when this information is not applicable, as in the case of clearly private value goods. We provide experimental evidence showing that bids in private-value auctions indeed depend on the bids made 
by others - a relationship we expect to find in common-value but not in private-value auctions.

To ensure purely private value situations and full information we use a novel hedonic stimulus: annoying sounds. This type of experience provides us with an experience that is direct, hedonic ${ }^{1}$, gives participants full information, and importantly is the type of experience that has no externalities and no possible trade. Eliciting values in our experiment is done using an incentive-compatible mechanism, either a BDM (Becker, De Groot, and Marschak 1964) procedure ${ }^{2}$ (in stage 1 of the experiment) or a second-price auction (in stage 2 of the experiment). We find that subjective values, or bids, are interrelated in the sense that observing others' past bids has a statistically significant effect on the bids participants subsequently submitted.

One implication of these results is that figuring out how much individuals are willing to pay, even for simple experiences, may be more complex, or less readily available, than we usually consider. As a consequence of this complexity we over-apply the strategy of using others' behavior as a guide and input for our making our own decisions. This tendency may explain some anomalous price behavior and fashion trends.

\section{The Experiment}

To make the point that participants' values are interrelated even in a situation of private values with perfect information, no externalities and with no trade, we recruited 45 students at the Massachusetts Institute of Technology. There were two stages, each with 10 rounds, to the experiment; in both stages, and in all rounds, participants bid for listening to an unpleasant tone over a headset. We used this artificial hedonic "good" for the following reasons: (1) we were able to provide subjects with a sample of the tone before they subsequently placed their bid, and as a result create a perfect information situation; (2) this is a purely subjective and personal experience; (3) there are no externalities; (4) there are no trading possibilities; and (5) to avoid a situation in which

1 That is, pleasurable and unpleasurable experiences.

2 A second price auction against a random number. 
subjects could solve the pricing problem by drawing on their own experiences. Unpleasant tones are not traded in the marketplace, so our subjects could not refer to similar decisions made outside the laboratory as a basis for their valuation. These aspects of the stimuli enable us to focus on the effect in which we are interested, if it exists (the procedure is similar to Ariely, Lowenstein, and Prelac 2003).

In the experiment we had two stages: in stage 1 we recorded the actual bids of a first group of participants. These bids where then used in stage 2 to study their influence on a second group of participants.

\section{Stage 1}

Upon arriving at the lab, at the beginning of stage 1, we explained that the study involves bidding and listening to high-pitched sound. We then explained the bidding procedure-the BDM procedure- a second-price auction against a random number. In our particular case the random number was drawn for a uniform distribution between 5 cents and 95 cents. According to this procedure, if a subject's bid was lower than the number drawn, the subject would win the auction $-\mathrm{s} /$ he would listen to the sound and get paid the random number drawn. Otherwise, the subject would not listen to the

sound, and would not get paid. This procedure was explained in detail before the start of the experiment, and we stressed its incentive compatibility property, including a few examples to show that bidding one's true value is the optimal strategy. Then subjects listened to the sound on their headphones for 10 seconds, and immediately after this first experience with the unpleasant tone, participants were asked to bid, meaning to state the minimum amount of money they demanded in order to listen to the same tone again (Willingness to Accept or WTA). This pricing procedure was repeated nine times (10 trials). Table 1 presents summary statistics of bids on each trial. 
Table 1: Summary Statistics

\begin{tabular}{|c|c|c|c|c|}
\hline & Average & S.d. & Min & Max \\
\hline Trial 1 & 41 & 37 & 0 & 100 \\
\hline Trial 2 & 37 & 34 & 0 & 100 \\
\hline Trial 3 & 36 & 33 & 0 & 100 \\
\hline Trial 4 & 32 & 28 & 0 & 100 \\
\hline Trial 5 & 35 & 33 & 0 & 100 \\
\hline Trial 6 & 31 & 29 & 0 & 100 \\
\hline Trial 7 & 35 & 32 & 0 & 100 \\
\hline Trial 8 & 34 & 31 & 0 & 100 \\
\hline Trial 9 & 34 & 30 & 0 & 100 \\
\hline Trial 10 & 33 & 32 & 0 & 100 \\
\hline Overall & $\mathbf{3 5}$ & $\mathbf{3 2}$ & $\mathbf{0}$ & $\mathbf{1 0 0}$ \\
\hline
\end{tabular}

\section{Selection}

Out of the 22 participants in stage 1, 17 subjects gave their consent to use their bids in future auctions; of these 17 participants we retained 12, avoiding bidders who consistently bid extreme values such as zero. The summary statistics of the bids of the 12 selected participants are shown below in table 2 .

Table 2: Selection

\begin{tabular}{|c|c|c|c|c|}
\hline & Average & S.d. & Min & Max \\
\hline Trial 1 & 49 & 32 & 5 & 100 \\
\hline Trial 2 & 43 & 27 & 15 & 100 \\
\hline Trial 3 & 42 & 27 & 15 & 95 \\
\hline Trial 4 & 39 & 22 & 10 & 80 \\
\hline Trial 5 & 41 & 28 & 10 & 95 \\
\hline Trial 6 & 38 & 26 & 10 & 80 \\
\hline Trial 7 & 42 & 27 & 5 & 80 \\
\hline Trial 8 & 42 & 26 & 5 & 77 \\
\hline Trial 9 & 40 & 24 & 5 & 77 \\
\hline Trial 10 & 43 & 30 & 1 & 90 \\
\hline Overall & $\mathbf{4 2}$ & $\mathbf{2 6}$ & $\mathbf{1}$ & $\mathbf{1 0 0}$ \\
\hline
\end{tabular}

We then sorted the selected bids in each trial from low value to high value, and used the four lowest and four highest bids in each trial for the LOW and HIGH treatment of stage 2 , as is explained next. 


\section{Stage 2}

Stage 2 was similar to stage 1: participants were asked to bid the amount they were willing to accept for listening to the same unpleasant high-pitched tone on a headset. As in stage 1, participants were first exposed to the tone, and only then asked to place a bid. However, in stage 2 subjects participated in a second-price auction, instead of the BDM procedure used in Stage 1. In the instructions, the notion of a second-price auction was explained, and it was stressed that it is an incentive compatible mechanism, meaning that the participants' best strategy is to bid their true value. Subjects were told they would participate in several trials of a second-price auction against four other bidders, and that these subjects had already placed their bids a few days earlier. The instructions followed: "In order to become familiar with the task, bids in the first round will be displayed to you momentarily ... you will start bidding only in the second round."

Hence, starting in the second round subjects were asked to place their bid, meaning to state the minimum amount of money they would accept (their price) in order to listen to the same tone again (WTA). If the subject won the auction, she listened to the tone and earned the second-lowest bid in the auction (equal or greater than her bid). After each auction, the other four bids were shown to the subject. This procedure was repeated nine times, to complete 10 trials.

We had two treatments, HIGH and LOW: in each trial subjects participated in a second-price auction against either the four highest (HIGH treatment) or four lowest (LOW treatment) bids of retained bids for the same trial in stage 1. For example, in the first trial the participating bids in the HIGH treatment were $[100,99,60,80]$, and in the LOW treatment were [20, 25, 5, 20]. In subsequent trials (trial 2 through 10) the set of bids retained from stage 1 in each treatment (HIGH and LOW) was very similar to the bids shown above.

At the end of stage 2 we requested feedback by asking the subjects what was their bidding strategy. Out of the 23 participants who participated in stage 2, one indicated 
s/he did not understand the auction and was confused. Another indicated s/he was testing the program to see whether the study was for real by, for instance, bidding 500 in one trial. As a result, we excluded these two participants when analyzing the data.

The results of Stage 2 are shown in figure 1 with mean bids in HIGH and LOW treatments, and table 3 showing these differences are significant in all trials $(\mathrm{p}<.03)$.

Figure 1: Main Results

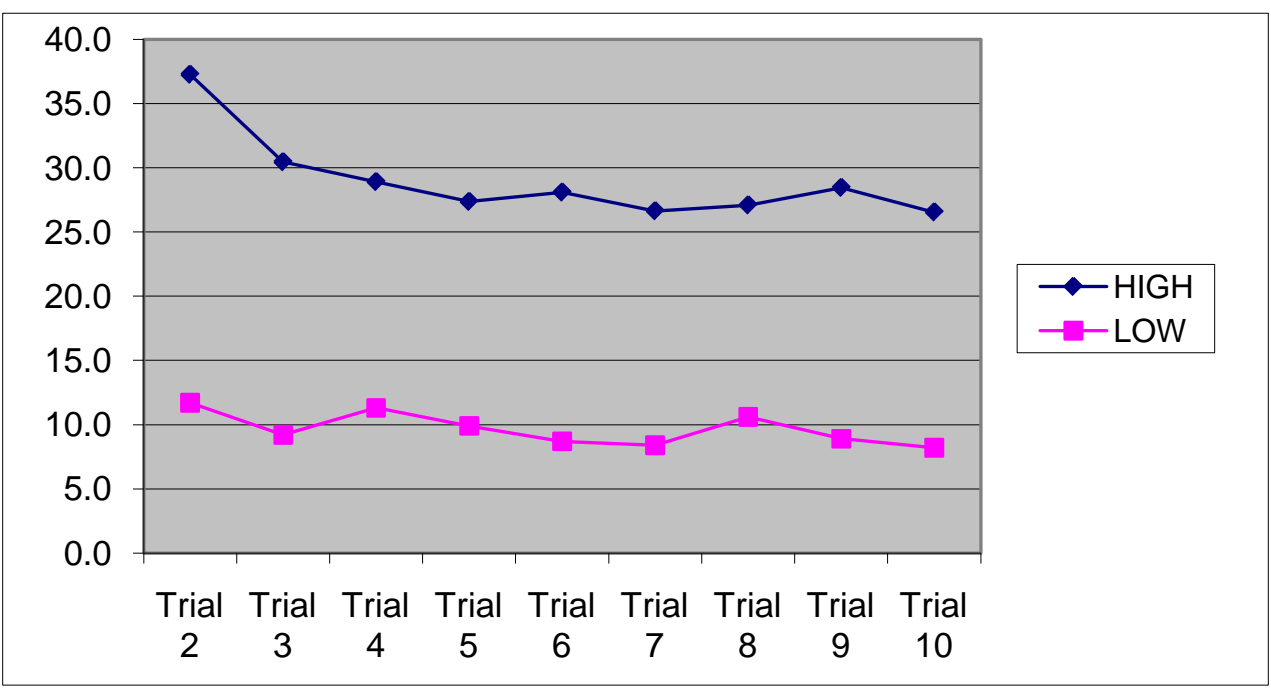

Table 3: Main Results

\begin{tabular}{|c|c|c|c|}
\hline & HIGH & LOW & p-val \\
\hline Trial 2 & 37.3 & 11.7 & 0.022 \\
\hline Trial 3 & 30.5 & 9.2 & 0.015 \\
\hline Trial 4 & 28.9 & 11.3 & 0.027 \\
\hline Trial 5 & 27.4 & 9.9 & 0.015 \\
\hline Trial 6 & 28.1 & 8.7 & 0.009 \\
\hline Trial 7 & 26.6 & 8.4 & 0.011 \\
\hline Trial 8 & 27.1 & 10.6 & 0.025 \\
\hline Trial 9 & 28.5 & 8.9 & 0.010 \\
\hline Trial 10 & 26.5 & 8.2 & 0.019 \\
\hline Overall & 28.97 & 9.65 & \\
\hline
\end{tabular}




\section{Discussion}

Our question is whether looking at other people's pricing decisions is a type of heuristic, a decision rule that people over-apply even when it is not appropriate, as in the case of clearly private value goods. We find evidence that this is indeed the case-an individual's valuation of a purely subjective experience is highly influenced by the value others place on a similar experience. These results might be useful when thinking about value formation and pricing in actual markets. If the valuations of others affect an individual's valuation this can lead to rigidities (of price or quantities), and seemingly create a common value even in the absence of one, as in the case of fashion trends. This adds an aspect to firm-consumer interactions and gives an additional explanation as for why firms hire experts or public-opinion shapers. Beyond the role of information, firms may hire experts or public-opinion shapers to generate consumers' value and, in turn, economic rents. This view of interrelated private valuations not only has interesting industrial organization and marketing implications and applications, as described above, but also has macroeconomics effects. For instance, interrelated private valuations can help explain the origins of nominal rigidities: those consumers who cannot translate their subjective valuation into monetary units, as is the case in our experiment, may rely on the prices others are willing to pay. In such a case prices will be sticky. 


\section{References}

Ariely, Dan, George Loewenstein, and Drazen Prelec. 2003. "'Coherent Arbitrariness': Stable Demand Curves Without Stable Preferences." The Quarterly Journal of Economics 118(1): 73-105.

Asch, Solomon E. 1951. "Effects of Group Pressure upon the Modification and Distortion of Judgment." In Groups, Leadership, and Men, ed. Harold Guerzkow, 177-190. Pittsburgh: Carnegie Press.

Banerjee, Abhijit V. 1992. “A Simple-Model of Herd Behavior.” The Quarterly Journal of Economics 107(3): 797-817.

Becker, Gordon M., Morris H. DeGroot, and Jacob Marschak. 1964, "Measuring Utility by a Single-Response Sequential Method." Behavioral Science 9(3): 226-232.

Bikhchandani, Sushil, David Hirshleifer, and Ivo Welch. 1992. "A Theory of Fads, Fashion, Custom, and Cultural-Change as Informational Cascades." Journal of Political Economy 100(5): 992-1026.

Petty, Richard E., and Duane T.Wegener. 1998. "Attitude Change: Multiple Roles for Persuasion Variables." In The Handbook of Social Psychology, 4th Edition, ed. Daniel T. Gilbert, Susan T. Fiske, and Gardner Lindzey, 323-390. Boston: McGraw-Hill.

Simonsohn, Uri, and Dan Ariely. 2008. “When Rational Sellers Face Nonrational Buyers: Evidence from Herding on eBay. “ Management Science 54(9): 1624-1637. 